\title{
Experimental design for I,3-propanediol biosynthesis by K. Pneumoniae GLC29 using glycerol
}

\begin{abstract}
Biodiesel glycerol can be used for the production of 1,3-propanediol by bacteria. In this study on the production of 1,3-propanediol by Klebsiella pneumoniae GLC29 was possible to optimize media culture the production of 1,3-propanediol using statistical experimental design techniques and response surface methodology, where 11 variables were tested and only 5 were found significant (glycerol, yeast extract, ammonium sulfate, vitamin B12 and fumarate). Subsequently, production of 1,3-propanediol was verified in 0,75 liter reactors, both in batch and exponential fed-batch. It was possible to achieve $23.6 \mathrm{~g} / 1$ of 1,3-propanediol in batch cultures using pure glycerol, $27 \mathrm{~g} / 1$ of 1,3 -propanediol in batch cultures using biodiesel glycerol, and $29.9 \mathrm{~g} / 1 \mathrm{of}$ 1,3-propanediol in exponential fed-batch using biodiesel glycerol.
\end{abstract}

Keywords: glycerol; biodiesel, 1,3-propanediol, klebsiella pneumonieae, surface response, batch, fed-batch, optimization
Volume 4 Issue 3 - 2017

\author{
Paulo Marcelo Avila Neto,' Gervásio Paulo \\ da Silva, ${ }^{2}$ Luciana Fontes Coelho,' Jonas \\ Contiero' \\ 'Depto de Bioquímica e Microbiologia, UNESP-Univ Estadual \\ Paulista, Brazil \\ ${ }^{2}$ Lab de Biotecnologia de Microrganismos, Univ do Estado da \\ Bahia, Brazil
}

\begin{abstract}
Correspondence: Jonas Contiero, UNESP-Univ Estadual Paulista. Instituto de Biociências de Rio Claro, Depto de Bioquímica e Microbiologia, Av 24A, I5 I5. Bela Vista, Rio ClaroSP Brazil,Tel +55 19 3526-4I70, Email jconti@rc.unesp.br
\end{abstract}

Received: March 28, 2017 | Published: November 30, 2017
Abbreviations: 1,3-PDO, 1,3-propanediol; PTT, polytrimethylene terephthalate; PET, polyethylene; 1,2-PDO, 1,2-propanediol; PHAs, poly hydroxy alkanoates; DHA, di-hydroxy acetone; 3-HPA, 3-hydroxy propion aldehyde; DoE, design of experiments; HPLC, high performance liquid chromatography

\section{Introduction}

Most of the energy consumed in the world comes from fossil fuels such as petrol, coal and natural gas. It is almost unanimous in the literature that these sources are limited and it is expected its exhaustion in the future. Nevertheless, there is a continued growth in consumption, at an average rate of 3\% per year worldwide since 1985 . However oil reserves commercially exploitable grow at lower rates than consumption. ${ }^{1}$

Search for alternative sources have been studied worldwide. In this context, biofuels are an alternative to replace oil-based fuels, and the use of biomass for production a promising alternative, as its demand is growing rapidly. ${ }^{2}$ Studies already show that the use of biomass for energy purposes has a increasing participation into the world energy matrix, and by the year 2050, the use of available biomass is expected to double worldwide. ${ }^{3}$

The use of vegetable oils for the biodiesel production generates $1 \mathrm{~kg}$ of byproduct glycerol for each $10 \mathrm{~kg}$ of biodiesel obtained. ${ }^{4,5}$ Glycerol conversion to other molecules is a challenge and an alternative to reduce the costs from biodiesel production. ${ }^{6}$ However, new applications are being studied for large volumes of biodiesel glycerol, since it can't be used in food and cosmetics industries without a cleaning and refining process. ${ }^{7}$ Glycerol may be used as carbon source in bioprocesses, and several species among the genera Clostridium, Citrobacter, Klebsiella and Pseudomonas ${ }^{5,7-13}$ are being studied for the biotransformation of glycerol from biodiesel to specialty chemicals. One promising solution is the use of biodiesel glycerol to produce 1,3-propanediol (1,3-PDO) by Klebsiella pneumoniae and Clostridium butyricum. ${ }^{14,15}$ 1,3-PDO is known for over 100 years, and its industrial scale production was done by two chemical processes, both produced toxic intermediates, and required reduction step under high hydrogen pressure and expensive catalysts. ${ }^{16,17}$ It is widely used for production of polymers, like Polytrimethylene terephthalate (PTT), which is known for its elastic properties, widely used in the manufacture of resins, adhesives, aqueous inks, laminates, coatings, moldings, aliphatic polyesters and antifreeze. 1,3 PDO also can be used in same applications such as ethylene glycol, propylene glycol, 1,3-butanediol and 1,4-butanediol are used. Moreover, as the production of polyethylene (PET) and PTT are analogous processes, it is possible to convert PET industrial plants to production of PTT, costing about $10-20 \%$ from the total amount of building a new industry. PTT has the same resistance from PET, and the advantage of having a more rapid crystallization, lower melting point and lower molding temperature. ${ }^{18}$ With a wide variety of applications, it's estimated that in 2020 , there will be a potential market of 230000 tons per year of 1,3-PDO. ${ }^{9}$

Fermentative glycerol metabolism can produce various biochemicals, such as 1,2-propanediol (1,2-PDO), 3-hydroxypropionic acid, lactate, succinate, polyhydroxyalkanoates (PHAs), L-phenylalanine, but also biofuels, such as ethanol and hydrogen. ${ }^{19}$ Several studies with Klebsiella pneumoniae, Citrobacter freundii, Clostridium butyricum and C. acetobutilicum, shown they are able to convert the residual glycerol from biodiesel to 1,3-PDO anaerobically. C. butyricum is capable of producing dihydroxyacetone, ethanol, acetate, and butyrate. ${ }^{9}$ The global market for bioenergy and biochemicals from biomass is estimated to reach 150 billion dollars by 2050 . Similarly the bio refinery market is expanding rapidly. For example, 3-hydroxypropionic acid (3-HPA) is the $3 \mathrm{rd}$ biochemical among the top 12 high value-added products ranked by the US Department of Energy, and it can be produced from biomass, ${ }^{19}$ including glycerol using part of Klebsiella pneumoniae enzyme machinery. The global market for 3-HPA was estimated to be 3.63 million tons per year.

New naturally occurring bacterial strains and species able to produce 1,3-PDO continue to be discovered like lactic acid bacteria, 
new species of Clostridia and even a thermophile, Caloramator viterbensis, which might have an interesting heat tolerant enzyme machinery for 1,3-PDO biosynthesis. For a large number of bacteria, including Citrobacter, Clostridium, Enterobacter, Klebsiella, and some Lactobacillus species, a consequence of anaerobic growth on glycerol is the generation of excessive reducers in the form of NADH. The regeneration of NAD requires the formation of a byproduct to serve as an electron sink. Enzymatic pathways for oxidation and reduction of glycerol were incorporated and used when glycerol is present and alternative carbon sources such as glucose are absent. ${ }^{20}$

The production of 1,3-propanediol is connected to an oxidative process of glycerol. Glycerol enters the cell by $g l p F$ (glycerol facilitated transport), or by diffusion. ${ }^{18}$ When it enters the cell, it can follow two routes. At the first, suffers oxidative dehydrogenation by a NAD+ dependent glycerol dehydrogenase, becoming dihydroxyacetone (DHA). DHA is next phosphorylated to dihydroxyacetone phosphate by an ATP-dependent DHA kinase. ${ }^{5,21}$ Through the parallel process, glycerol is dehydrated to form 3-hydroxypropionaldehyde (3HPA) by glycerol dehydratase (EC 4.2.1.30), in $K$. pneumoniae case, B12-dependent, composed of 3 peptides, encoded by dhaB1, $d h a B 2$, and dhaB3. Then, 3-HPA is reduced to 1,3-PDO by 1,3-PDO oxidoreductase (EC 1.1.1.202) linked to NADH.

In $K$. pneumoniae, the overall reductive reaction rate is limited, firstly because this reaction is mediated by cyanocobalamin (vitamin B12). Furthermore, there may happen substrate inhibition, with an irreversible binding of cobalamin with the enzyme to form alkylcobalamines. However, reactivation factors, encoded by genes $g d r A$ and $g d r B$ (or $d h a F$ and $d h a G$ ), swap the inactivated cobalamin for a new molecule of vitamin B12, requiring the presence of magnesium ions $\left(\mathrm{Mg}^{2+}\right)$ and with consumption of 1 ATP. The resultant Apo enzyme rebinds coenzyme B12, and glycerol conversion to 3-HPA resumes.

Traditional techniques for multivariate optimization systems are not only time consuming but also don't show interactions among the factors tested. They require a large number of experiments to determine optimal points, which are usually not reproducible or statistically significant. Design of experiments (DoE) is an alternative to improve processes and to investigate correlations and synergistic or antagonistic interactions between factors tested collectively, minimizing the number of experiments, and it is possible to analyze the results using a response surface method..$^{15,22}$

The objective of this work was to optimize production of 1,3-propanediol media culture of a new strain of Klebsiella pneumoniae GLC29 isolated by Da Silva et al. ${ }^{2}$

\section{Material and methods}

\section{Strain studied and maintenance of isolates}

The microorganism K. pneumoniae CLG29 was previously isolated by Da Silva et al., ${ }^{2}$ and kept at $-86^{\circ} \mathrm{C}$ in $20 \%$ glycerol solution or lyophilized. Subcultures were performed regularly to maintain the viability of the cultures. Cultures were reactivated in test tubes with $5 \mathrm{~mL}$ of Luria Berthani (LB) and incubated at $37^{\circ} \mathrm{C}$ for $12-24 \mathrm{~h}$.

To the micro-organism identification, DNA from the $16 \mathrm{~S}$ region was amplified using primers $8 \mathrm{~F}$ and $1492 \mathrm{R}$ and Taq polymerase in a standard PCR reaction. The isolated DNA was treated with Big Dye Polymerase kit prior to sequencing. Sequences were aligned using MEGA 5.0 and ClustalW softwares using the Neighbor-Joining method. ${ }^{23}$

\section{Inoculum and fermentation conditions}

Inoculum was prepared using LB media for 12-16 hours. Fermentations were performed in rotatory shaker at $37^{\circ} \mathrm{C}$ and $100 \mathrm{rpm}$ for $8-24 \mathrm{~h}$ in $125 \mathrm{~mL}$ Erlenmeyer flasks containing $50 \mathrm{~mL}$ of synthetic medium (g/l): $\left(\mathrm{NH}_{4}\right)_{2} \mathrm{PO}_{4} 5.0, \mathrm{~K}_{2} \mathrm{HPO}_{4} 1.5 ; \mathrm{NaCl} 1.0$, and $1 \mathrm{~mL}$ of trace elements stock solution (g/l): EDTA $0.5, \mathrm{CaCl}_{2} .2 \mathrm{H}_{2} \mathrm{O} 0.5, \mathrm{CoCl}_{2} \cdot 6 \mathrm{H}_{2} \mathrm{O}$ $0.16 ; \mathrm{MoNH}_{4} \cdot 4 \mathrm{H}_{2} \mathrm{O} 0.1, \mathrm{CuSO}_{4} \cdot 5 \mathrm{H}_{2} \mathrm{O} 0.16 ; \mathrm{FeSO}_{4} \cdot 7 \mathrm{H}_{2} \mathrm{O} 0.5, \mathrm{MnSO}_{4}$. $\mathrm{H}_{2} \mathrm{O} 0.5, \mathrm{ZnSO}_{4} .7 \mathrm{H}_{2} \mathrm{O} 0.22, \mathrm{NiCl}_{2} .6 \mathrm{H}_{2} \mathrm{O} 0.03, \mathrm{H}_{3} \mathrm{BO}_{3} 0.12$. Carbon and nitrogen sources, along with salts and vitamins concentrations were determined in the experimental design. Experimental designs and batch cultures in fermenter vessels were performed with media components as optimized in the experimental designs discussed in results section. Synthetic Media for those experiments were the same as described above. Batch fermentations were performed on a Multifors Fermenter, at $37^{\circ} \mathrm{C}, 100 \mathrm{rpm}$, and $\mathrm{pH}$ control (pH 6.8), and nitrogen gas was added to purge the oxygen out of the vases.

Periodically, samples of $1 \mathrm{~mL}$ were collected from the cultures and centrifuged at $10,000 \mathrm{~g}$ for 10 minutes. The cell-free supernatant was filtered $(0.22 \mu \mathrm{m})$ and analyzed by high performance liquid chromatography (HPLC) using ion exchange column Phenomenex Rezex ROA (300mmx7.8mm) at a temperature of $60^{\circ} \mathrm{C}$ and $0.005 \mathrm{M}$ of $\mathrm{H}_{2} \mathrm{SO}_{4}$ water solution as mobile phase and flow of $0.5 \mathrm{~mL} / \mathrm{min}$. External standards used were ethanol, 1,3- propanediol, propionic acid, acetic acid, 2,3-butanediol and glycerol.

Microbial growth was quantified by reading the optical density and correlated to dry cell mass by simple linear correlation. Successive dilutions of cell suspension and readings are made using optical spectrophotometry at $600 \mathrm{~nm}$ (DO 600nm) with readings in the range of 0.2 to 0.8 absorbance. The Total Dry Mass was multiplied by the inverse of the dilutions made, and correlated with the absorbance values obtained and verified using linear correlation and Pearson's correlation coefficient.

\section{Optimization using experimental design}

Techniques of fractional factorial design and full factorial design to screen factors that influence microbial growth and production of 1,3-Propanediol were used. Five replicates of each the center point were performed to determine experimental error and calculate ANOVA. The significant level $\mathrm{p}<0.05$ or $\mathrm{p}<0.1$ for screening methods was used. Pareto chart of effects were analyzed, and the absolute value of the standardized $(p<0.05$ or $p<0.1)$ effect represented in bars was calculated by dividing each coefficient by its standard error (Coef/ SE Coef).

Experimental designs were made to screen possible significant variables in the culture medium. Eleven variables were chosen to be screened and a Placket-Burman Fatorial DoE was executed with 5 central points and 4 dummy variables, which were used to calculate experimental error. Then, with less significant variables, it was performed a Box, Hunter \& Hunter Fatorial DoE and two Central Composite non factorial Surface response Designs with full resolution to observe interactions between the variables. Samples were taken every 8, 24 and 48 hours from the fermentation flasks. Experiments were performed always in replicates or triplicates, accordingly to the limitations imposed by the number of experiments and data obtained from ANOVA. 


\section{Results and discussion}

\section{Strain identification}

In order to confirm the strain species, DNA from the $16 \mathrm{~s}$ region was used as fingerprint and a evolutionary history was inferred using the Neighbor-Joining method. ${ }^{23}$ The optimal tree with the sum of branch length $=0.08674627$ is shown. The percentage of replicate trees in which the associated taxa clustered together in the bootstrap test (1000 replicates) are shown next to the branches. ${ }^{24}$ The tree (Figure 1) is drawn to scale, with branch lengths in the same units as those of the evolutionary distances used to infer the phylogenetic tree. The evolutionary distances were computed using the Maximum Composite Likelihood method ${ }^{25}$ and are in the units of the number of base substitutions per site. The analysis involved 20 nucleotide sequences. Codon positions included were $1^{\text {st }}+2^{\text {nd }}+3^{\text {rd }}+$ Non-coding. All positions containing gaps and missing data were eliminated. There were a total of 1225 positions in the final dataset. Evolutionary analysis were conducted in MEGA6. ${ }^{26}$ Based on the relationship with the consensus to the other Klebsiella pneumoniae strains and its relative species, the bacteria isolated by $\mathrm{Da} \mathrm{Silva}^{2}$ is a Klebsiella pneumoniae.

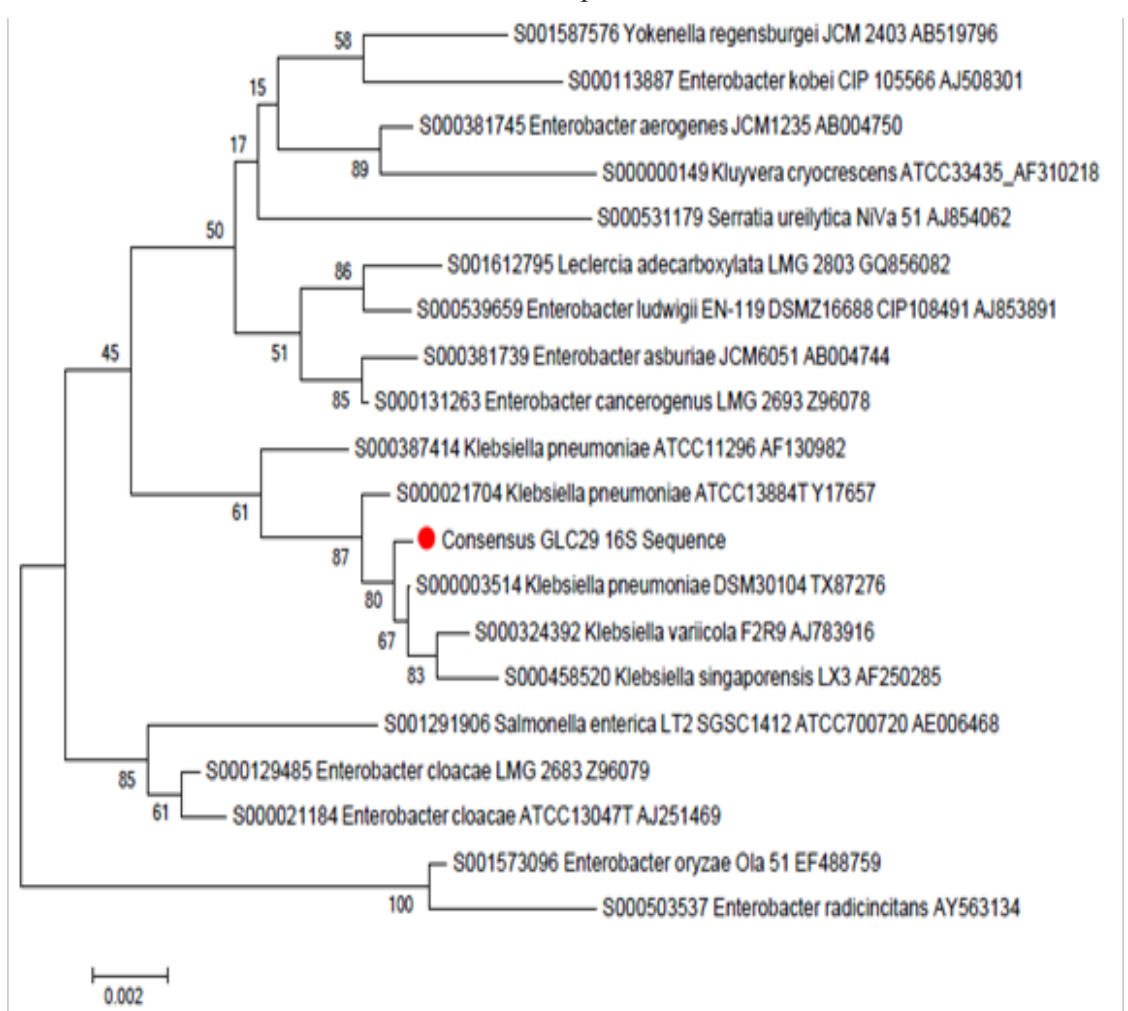

Figure I Evolutionary relationships of taxa from strain Klebsiella pneumoniae GLC29 (closed circle).

\section{Culture optimizations of klebsiella pneumoniae GLC29}

Placket-burman fatorial DoE: Eleven variables were chosen for culture media screening, based on the literature. We chose to experiment salts which might have influence on the known enzymes glycerol dehydratase (EC 4.2.1.30) and 1,3-propanediol oxidoredutase (EC 4.2.1.30) based on Brenda website database. ${ }^{27}$ Fermentations were performed as described on Material and Methods. Data from this experiment is shown on supporting material. Based on the Placket-Burman, ammonium sulfate, calcium chloride, yeast extract and inoculum percentage had positive impact on total 1,3-propanediol produced. Therefore, it is suggested that they must be kept for additional studies. Furthermore, $\mathrm{NaNO}_{3}, \mathrm{MgSO}_{4}$ and $\mathrm{ZnCl}_{2}$ had no significant impact on 1,3-PDO synthesis, so their removal from the media is recommended for the production. Glycerol, although had a negative influence on the total production, is the main carbon source and new experiments with lower concentrations were performed on the subsequent experiments. Vitamin B12 and fumaric acid also had a negative impact on production, but were kept as variables for the next optimizations.

Box, hunter \& hunter full fatorial DoE: Five factors from the previous Design of Experiments (DoE) were chosen for a Box, Hunther
\& Hunther Full Fatorial DoE: glycerol concentration, yeast extract, ammonium sulfate, vitamin B12 and fumaric acid. Inoculum concentration was fixed at $10 \%$, and $\mathrm{CaCl}_{2}$ at $5 \mathrm{mM}$. Other variables, which had no significant effect, were removed from the formulation. Fermentations were performed as described on Material and Methods. Table 1 shows decoded variables for this DoE. Table 2 shows ANOVA results for 1,3-PDO production after $24 \mathrm{~h}$ in flasks. With Box, Hunter \& Hunter full resolution DoE, it is possible to observe interactions between the variables. The interactions calculated are represented on the tables and graphs by the numbers of the independent variable by the other variable, i.e. 1 by 2 represents the interaction between Glycerol (1) and Yeast Extract (2), 4 by 5 represents the interaction between Vit. B12 and Fumarate, and so on. Variables with p-value $<0.05$ were considered significant. ANOVA resulted on a satisfactory $\mathrm{R}^{2}$ of $93 \%$ fit to the model, and ignoring the non-significant variables, the adjusted $\mathrm{R}^{2}$ resulted in a $89 \%$ fit to the model. For a good statistical model, the $\mathrm{R}^{2}$ value should be close to 1.0 , where a value greater than 0.75 indicates the aptness of the model. ${ }^{28}$ All independent variables selected from the Placket-Burman DoE screening were significant to the experiment, and also some interactions among them. Figure 2 shows the calculated effect of each variables and respective interactions between 
them. Glycerol up to $30 \mathrm{~g} / 1$, Vitamin B12 up to $500 \mu \mathrm{g} / 1$, Ammonium Sulfate up to $3 \mathrm{~g} / \mathrm{l}$, Fumarate up to $5 \mathrm{mM}$, Yeast Extract up to $7 \mathrm{~g} / \mathrm{l}$, and their interactions Glycerol with Vitamin B12, Glycerol and Yeast Extract, and Glycerol with Fumarate had a significant impact in 1,3-propanediol production. The interaction between Fumarate and Vitamin B12 (2 by 5 on Figure 2) had a negative effect on production, which negative slope (-2.51) completely annulled fumarate effect (2.31). Fumarate addition with vitamin B12 is not recommended, since it would have a higher cost in media formulation and the interaction between both components would result in the same or less production. Based on the results obtained from Box, Hunter \& Hunter design of experiments, Glycerol, Yeast Extract, Ammonium Sulfate and Vitamin B12 were chosen to be optimized by using Central Composite Rotational Design and surface response methodology. Since fumarate addition with vitamin B12 had negative interaction, fumaric acid was not used for the next optimization.

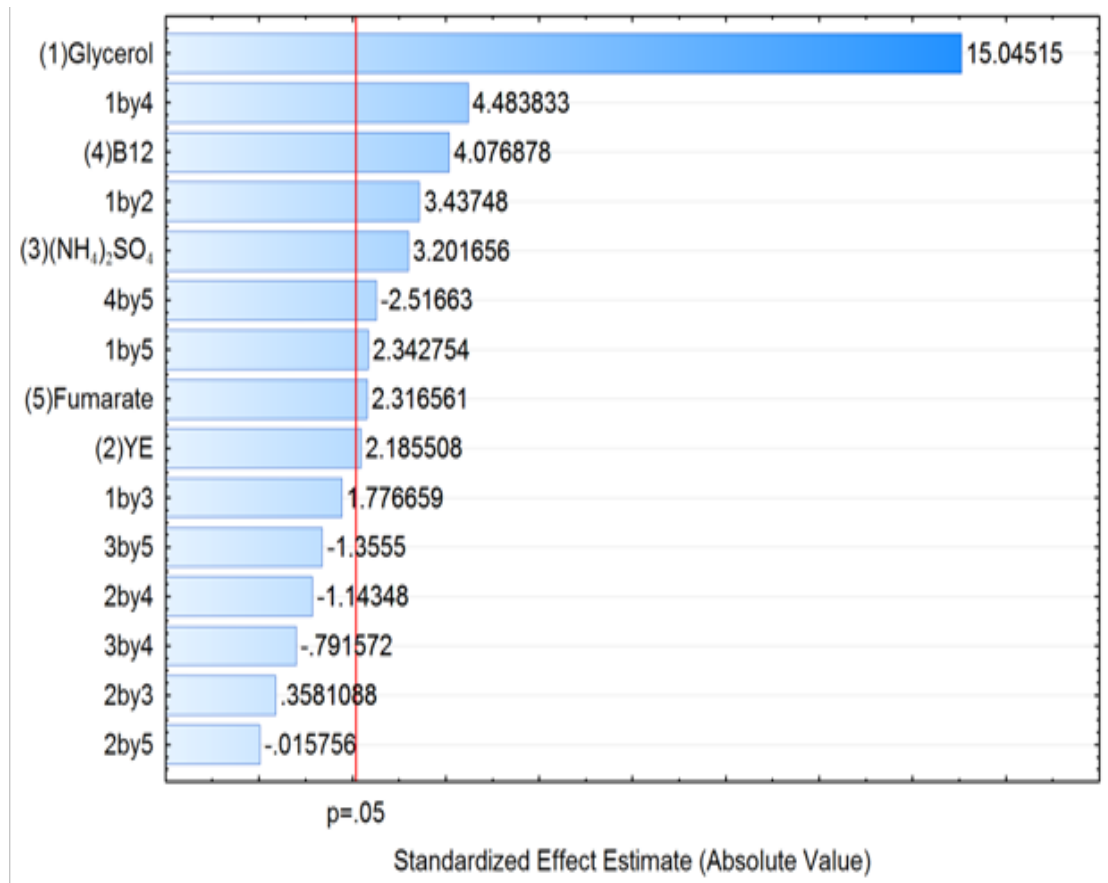

Figure 2 Culture Optimizations of Klebsiella pneumoniae GLC29: I,3-propanediol g/L at 24h cultivation Pareto chart of effects in Box, Hunter \& Hunter Full DoE 5 var. (Glycerol, $\mathrm{YE},\left(\mathrm{NH}_{4}\right)_{2} \mathrm{SO}_{4}$, Fumarate and Vit. BI2). Variables with $\mathrm{p}$-value $<0.05$ were considered significant.

Table I Box, hunter \& hunter full factorial design: decoded levels of the independent variables

\begin{tabular}{llll}
\hline \multirow{2}{*}{ Variable } & \multicolumn{3}{l}{ Levels } \\
\cline { 2 - 4 } & -I & $\mathbf{0}$ & $\mathbf{+ I}$ \\
\hline Glycerol $(\mathrm{g} / \mathrm{L})$ & 10 & 20 & 30 \\
Yeast Extract $(\mathrm{g} / \mathrm{L})$ & 3 & 5 & 7 \\
$\left(\mathrm{NH}_{4}\right)_{2} \mathrm{SO}_{4}(\mathrm{~g} / \mathrm{L})$ & 0 & 1.5 & 3 \\
Vitamin $\mathrm{BI}_{2}(\mu \mathrm{g} / \mathrm{L})$ & 0 & 250 & 500 \\
Fumarate $(\mathrm{mM})$ & 0 & 2.5 & 5 \\
\hline
\end{tabular}

Central composite, non-factorial, surface DoE: Four factors from the previous DoE (Box, Hunter \& Hunter) were chosen to optimization: glycerol concentration, yeast extract, ammonium sulfate, and vitamin $\mathrm{B} 12$. Inoculum concentration was fixed at $10 \%$, and $\mathrm{CaCl}_{2}$ at $5 \mathrm{mM}$. Table 3 demonstrates decoded values for the first Central Composite non-factorial Surface response DoE.

1,3-PDO production after 8 hours were beneficiated by higher amounts of glycerol, but a little but significant quadratic negative effect demonstrates that higher concentrations than $45 \mathrm{~g} / 1$ of glycerol is prejudicial to $1,3-\mathrm{PDO}$ production. The addition from $5 \mathrm{mg} / 1$ to $20 \mathrm{mg} / 1$ of vitamin B12, production was negatively impacted because of its interaction with glycerol. An irreversible binding of the vitamin B12 and glycerol with the enzyme, forms alkylcobalamines, and to avoid low activity of the enzyme, the amount of glycerol should be controlled,,$^{20,29-32}$ but also the amount of vitamin should be controlled. As a consequence of the normal catalytic cycle with glycerol, the coenzyme B12 is occasionally rendered inactive (B12-inact). The B12inact remains tightly bound to the dehydratase and catalysis ceases. An auxiliary enzyme, glycerol dehydratase reactivase, facilitates the dissociation of the B12-inact and glycerol dehydratase (EC 4.2.1.30). The resultant apoenzyme rebinds and glycerol conversion to 3-HPA resumes. ${ }^{20}$

Both linear and quadratic significant effects were observed for glycerol, but the linear effect was many times greater than the quadratic effect. Quadratic significance of yeast extract was observed, which means it was possible to obtain an optimum working region, but no significance was observed in ammonium sulfate using these concentrations for 1,3-propanediol production. Surface response graphs are shown on Figure 3. Up to $12 \mathrm{~g} / \mathrm{l}$ of 1,3-PDO was reached with this design. Higher concentrations, from $5 \mathrm{mg} / 1$ of this vitamin is not beneficial for 1,3-propanediol biosynthesis, especially when associated with glycerol, when $40 \mathrm{~g} / 1$ of glycerol and $20 \mathrm{mg} / \mathrm{l}$ of Vit. B12 are added.

No other significant interaction was observed, which means most of the variables act independent on 1,3-PDO synthesis. An optimum region was observed when yeast extract was plotted against $\left(\mathrm{NH}_{4}\right)_{2} \mathrm{SO}_{4}$, in which 3 to $5 \mathrm{~g} / \mathrm{l}$ of YE, and 2 to $4 \mathrm{~g} / \mathrm{l}$ of $\left(\mathrm{NH}_{4}\right)_{2} \mathrm{SO}_{4}$ could be optimal for 1,3-propanediol production. 

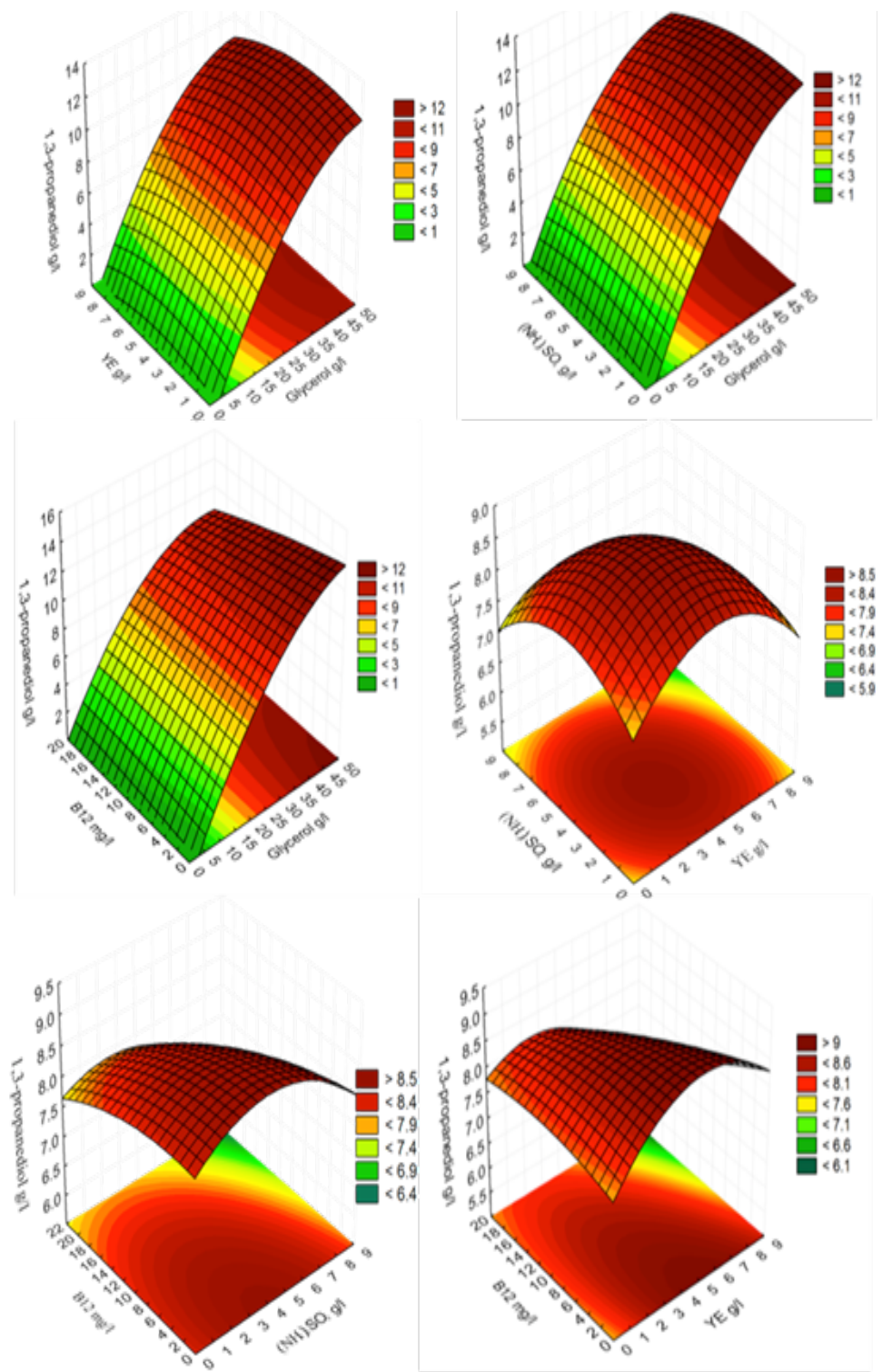

Figure 3 Surface response.

Table 4 shows the ANOVA results calculated for this experiment, where significant variables are shown in bold, which variables with p-value $<0.05$ were considered significant. Calculated F-value was higher than the tabled F-value. $\mathrm{R}^{2}$ for the calculated model 0.95 , which explains $95 \%$ of the results obtained. The addition from 1 to $4 \mathrm{mg} / \mathrm{l}$ of Vitamin B12 had no effect on production, and the addition of higher concentrations, from 5 to $20 \mathrm{mg} / 1$, as shown on first central composite non factorial DoE, had a negative effect on 1,3-propanediol production. Therefore, it is demonstrated that concentrations of $0.5 \mathrm{mg} / 1$ of vitamin B12 are more than enough to saturate the system.

Based on Box, Hunter \& Hunter DoE, and further Central Composite non factorial DoE, the optimum media recommended is $500 \mathrm{~g} / \mathrm{l}$ of vitamin $\mathrm{B} 12,2 \mathrm{~g} / \mathrm{l}$ of $\left(\mathrm{NH}_{4}\right)_{2} \mathrm{SO}_{4}, 3 \mathrm{~g} / \mathrm{l}$ of Yeast Extract and $49 \mathrm{~g} / \mathrm{l}$ of glycerol.

\section{Batch fermentation of $k$. pneumoniae GLC29}

Media components were optimized from the Experimental Design. Figure 4 shows the kinetics of 1,3-propanediol production using

analytical grade glycerol. After 9 hours, all glycerol was consumed and up $24.4 \mathrm{~g} / 1$ of 1,3-propanediol was produced. Figure 5 shows kinetics of 1,3-propanediol production in biodiesel glycerol, obtained from the biodiesel refinary Biocapital located in Charqueada-SP, Brazil. Biodiesel Glycerol, although had a longer fermentation (12 h), produced $27.6 \mathrm{~g} / 1$ of 1,3-propanediol out of $66 \mathrm{~g} / 1$ of biodiesel glycerol. These are an increase of $4 \mathrm{~g} / 1$ and $7.2 \mathrm{~g} / 1$ respectively since the last optimization of this strain by Da Silva et al. ${ }^{2}$ Table 5 and 6 show the obtained data, specific growth, glycerol consumption, yields and productivity for each batch, respectively. Maximum productivity was $2.56 \mathrm{~g} / \mathrm{l}$.h using analytical grade glycerol and $2.3 \mathrm{~g} / \mathrm{l}$.h for biodiesel glycerol, and $\mathrm{Yp} / \mathrm{s}$ was $0.46 \mathrm{~g} / \mathrm{g}$ and $0.43 \mathrm{~g} / \mathrm{g}$ respectively.

Comparing to Da Silva et al., ${ }^{2}$ which had a maximum productivity of $2.92 \mathrm{~g} / \mathrm{l} . \mathrm{h}$ and a yield of 0.51 from $40 \mathrm{~g} / \mathrm{l}$ of glycerol, the results obtained from this work focused on maximum production, and although concentrations above $49 \mathrm{~g} / 1$ inhibits the productivity, ${ }^{2}$ and lower productivity was obtained, media can be re-adjusted and recalculated using the experimental design. 
Table 2 ANOVA; Var: I,3-propanediol at 24h; $R^{2}=0.93 ;$ Adjusted $R^{2}: 0.89$ (Results DoE Box, Hunter \& Hunter 5 var. (Glycerol, $\mathrm{YE},\left(\mathrm{NH}_{4}\right)_{2} \mathrm{SO}_{4}$, Fumarate and Vit. BI2)

\begin{tabular}{|c|c|c|c|c|c|}
\hline & SS & df & MS & $\mathbf{F}$ & $\mathbf{p}$ \\
\hline Glycerol & 139.22 & I & 139.22 & 226.36 & 0 \\
\hline YE & 2.94 & 1 & 2.94 & 4.78 & 0.04 \\
\hline$\left(\mathrm{NH}_{4}\right)_{2} \mathrm{SO}_{4}$ & 6.3 & I & 6.3 & 10.25 & 0 \\
\hline $\mathrm{B} 12$ & 10.22 & I & 10.22 & 16.62 & 0 \\
\hline Fumarate & 3.3 & I & 3.3 & 5.37 & 0.03 \\
\hline 1 by 2 & 7.27 & I & 7.27 & 11.82 & 0 \\
\hline I by 3 & 1.94 & I & 1.94 & 3.16 & 0.09 \\
\hline I by 4 & 12.37 & I & 12.37 & 20.1 & 0 \\
\hline 1 by 5 & 3.38 & I & 3.38 & 5.49 & 0.03 \\
\hline 2 by 3 & 0.08 & I & 0.08 & 0.13 & 0.72 \\
\hline 2 by 4 & 0.8 & I & 0.8 & 1.31 & 0.27 \\
\hline 2 by 5 & 0 & I & 0 & 0 & 0.99 \\
\hline 3 by 4 & 0.39 & 1 & 0.39 & 0.63 & 0.44 \\
\hline 3 by 5 & 1.13 & I & 1.13 & 1.84 & 0.19 \\
\hline 4 by 5 & 3.9 & I & 3.9 & 6.33 & 0.02 \\
\hline Error & 12.92 & 21 & 0.62 & & \\
\hline Total SS & 206.14 & 36 & & & \\
\hline
\end{tabular}

SS, sum of squares; $d f$, degrees of freedom; MS, mean squared; F, calculated $f$ value for the f-test.; $p, p$ value

Table 3 Central composite non-factorial surface response, design: decoded levels for optimizing culture media.

\begin{tabular}{llllll}
\hline \multirow{2}{*}{ Variables } & $-\alpha$ & $-I$ & 0 & 1 & $+\alpha$ \\
\cline { 2 - 6 } & 5 & 10 & 20 & 30 & 45 \\
\hline Glycerol $(\mathrm{g} / \mathrm{L})$ & 0 & 2 & 4 & 6 & 8 \\
Yeast Extract $(\mathrm{g} / \mathrm{L})$ & 0 & 2 & 4 & 6 & 8 \\
$\left(\mathrm{NH}_{4}\right)_{2} \mathrm{SO}_{4}(\mathrm{~g} / \mathrm{L})$ & 0 & 5 & 10 & 15 & 20 \\
Vitamin BI2 $(\mathrm{mg} / \mathrm{L})$ & & & & &
\end{tabular}

Glycerol concentration must be controlled because of 3-hydroxypropionaldehyde inhibition, which is an intermediate metabolite in the conversion of glycerol to 1,3-propanediol. The 3-hydroxypropionaldehyde accumulation during fermentation has been described in anaerobic fermentation by K. pneumoniae, and when the initial glycerol concentration was superior to $430 \mathrm{mM}$, a high concentration of 3-HPA inhibited cell growth and production of 1,3-propanediol..$^{33,34}$ Zheng et al. ${ }^{35}$ had demonstrated a productivity of $1.81 \mathrm{~g} / \mathrm{l}$.h from $50 \mathrm{~g} / \mathrm{l}$ of glycerol, controlling $\mathrm{pH}$, aeration rate and stirring in the bioreactor at 6,48, $0.6 \mathrm{VVM}$ and $318 \mathrm{rpm}$, respectively, and the yield and productivity of $71.03 \mathrm{~g} / 1,2.37 \mathrm{~g} / \mathrm{l} . \mathrm{h}$ respectively and $0.6425 \mathrm{~mol} / \mathrm{mol}(1,3-\mathrm{PDO} / \mathrm{glycerol})$ at a fermentation of $30 \mathrm{~h}$ with the initial glycerol, rate of stirring, air aeration and $\mathrm{pH}$ of $50 \mathrm{~g} / 1,320 \mathrm{rpm}$, $0.6 \mathrm{VVM}$ and 6.5 by fed-batch fermentation maintaining glycerol to $20-30 \mathrm{~g} / 1$.

To optimize 1,3-propanediol synthesis, two stage processes are ideal, in which cells can be cultured first in a rich medium, and 1,3-propanediol production may be induced by addition of glycerol on the stationary phase. Another strategy may be supplementing glycerol during fermentation. Both processes have increased the production of 1,3-propanediol during fermentation by Klebsiella pneumoniae overexpression of $d h a T^{36}$

Table 4 ANOVA results calculated

\begin{tabular}{|c|c|c|c|c|c|}
\hline & SS & df & MS & $\mathbf{F}$ & $\mathbf{p}$ \\
\hline Glycerol g/L (L) & 318.53 & I & 318.53 & 873.07 & 0 \\
\hline Glycerol g/L (Q) & 9.81 & I & 9.81 & 26.88 & 0 \\
\hline YE g/L (L) & 0.03 & 1 & 0.03 & 0.09 & 0.76 \\
\hline YE g/L (Q) & 1.82 & I & 1.82 & 4.99 & 0.03 \\
\hline$\left(\mathrm{NH}_{4}\right)_{2} \mathrm{SO}_{4} \mathrm{~g} / \mathrm{L}(\mathrm{L})$ & 0.48 & I & 0.48 & 1.32 & 0.26 \\
\hline$\left(\mathrm{NH}_{4}\right) 2 \mathrm{SO}_{4} \mathrm{~g} / \mathrm{L}(\mathrm{Q})$ & I & I & I & 2.74 & 0.11 \\
\hline Vit. BI 2mg/L (L) & 2.73 & I & 2.73 & 7.48 & 0.01 \\
\hline Vit. BI 2mg/L (Q) & 0.11 & I & 0.11 & 0.31 & 0.58 \\
\hline IL by $2 \mathrm{~L}$ & 0.06 & I & 0.06 & 0.17 & 0.69 \\
\hline IL by $3 \mathrm{~L}$ & 0.36 & I & 0.36 & 0.98 & 0.33 \\
\hline IL by $4 \mathrm{~L}$ & 1.8 & I & 1.8 & 4.93 & 0.03 \\
\hline $2 \mathrm{~L}$ by $3 \mathrm{~L}$ & 0.1 & I & 0.1 & 0.28 & 0.6 \\
\hline $2 \mathrm{~L}$ by $4 \mathrm{~L}$ & 0.54 & I & 0.54 & 1.49 & 0.23 \\
\hline $3 \mathrm{~L}$ by $4 \mathrm{~L}$ & 0.07 & 1 & 0.07 & 0.2 & 0.66 \\
\hline Error & 14.59 & 40 & 0.36 & & \\
\hline Total SS & 349.86 & 54 & & & \\
\hline
\end{tabular}

The boiling points of 2,3-butanediol, 1,3-PDO and glycerol are $184^{\circ} \mathrm{C}, 214^{\circ} \mathrm{C}$ and $290^{\circ} \mathrm{C}$ respectively at normal pressure. In fact, it is a challenge to separate 1,3-PDO from a fermentation mixture. But in comparison with the chemical synthesis, which produces 1,2-propanediol, 1,3-PDO purification is even more difficult. Therefore, microbial production of 1,3-PDO may cost $50-70 \%$ of the total cost for production of 1,3-PDO. Consequently, the downstream plays an important role in the industrial microbial production. ${ }^{37}$ 
Table 5 Batch Culture of K. pneumoniae GLC29 in Analytical grade Glycerol. DCW: Dry Cell Weight; I,3-PDO; I,3-propanediol

\begin{tabular}{|c|c|c|c|c|c|c|c|c|c|c|c|}
\hline \multirow{2}{*}{$\begin{array}{l}\text { Time } \\
\text { (h) }\end{array}$} & \multicolumn{3}{|c|}{ Obtained data } & \multicolumn{3}{|c|}{ Specific rates } & \multicolumn{3}{|c|}{ Yields } & \multicolumn{2}{|c|}{ Productivity } \\
\hline & $\begin{array}{l}\text { DCW } \\
X(g / L)\end{array}$ & $\begin{array}{l}\text { Glycerol } \\
\text { S(g/L) }\end{array}$ & $\begin{array}{l}\text { I,3-PDO } \\
\text { P(g/L) }\end{array}$ & $\begin{array}{l}\mu \mathrm{X} \\
\left(\mathbf{h}^{-1}\right)\end{array}$ & $\begin{array}{l}\boldsymbol{\mu S} \\
\left(\mathbf{h}^{-1}\right)\end{array}$ & $\begin{array}{l}\boldsymbol{\mu P} \\
\left(\mathbf{h}^{-1}\right)\end{array}$ & $\begin{array}{l}A_{x / s} \\
(g / g)\end{array}$ & $\begin{array}{l}A_{x / p} \\
(g / g)\end{array}$ & $\begin{array}{l}Y_{p / s} \\
(g / g)\end{array}$ & $\begin{array}{l}P_{p} \\
\text { (g/L.h) }\end{array}$ & $\begin{array}{l}P_{\text {ox }} \\
\text { (g/L.h) }\end{array}$ \\
\hline 0 & 0.07 & 51.05 & 0 & 0 & 0 & 0 & 0 & 0 & 0 & 0 & 0 \\
\hline 1 & 0.15 & 51.04 & 0.12 & 0.65 & 5.8 & 1.32 & 6.39 & 0.69 & 9.23 & 0.12 & 0.08 \\
\hline 2 & 0.27 & 49.3 & 0.4 & 1 & 7.07 & 3.32 & 0.11 & 0.49 & 0.23 & 0.2 & 0.1 \\
\hline 3 & 0.68 & 47.29 & 1.88 & 0.51 & 4.24 & 3.49 & 0.16 & 0.33 & 0.5 & 0.63 & 0.2 \\
\hline 4 & 0.95 & 43.53 & 5.15 & 0.52 & 3.95 & 3.7 & 0.12 & 0.17 & 0.68 & 1.29 & 0.22 \\
\hline 5 & 1.68 & 39.76 & 8.94 & 0.33 & 4.94 & I.87 & 0.14 & 0.18 & 0.79 & 1.79 & 0.32 \\
\hline 6 & 2.05 & 26.94 & 11.44 & 0.17 & 5.06 & 2.13 & 0.08 & 0.17 & 0.47 & 1.91 & 0.33 \\
\hline 7 & 2.37 & 18.97 & 17.69 & 0.16 & 3.76 & 1.9 & 0.07 & 0.13 & 0.55 & 2.53 & 0.33 \\
\hline 8 & 2.79 & 9.08 & 20.47 & 0.11 & 3.13 & 0.96 & 0.06 & 0.13 & 0.49 & 2.56 & 0.34 \\
\hline 9 & 2.97 & 1.52 & 23.02 & 0.03 & 1.22 & 0.5 & 0.06 & 0.13 & 0.46 & 2.56 & 0.32 \\
\hline
\end{tabular}

Table 6 Batch culture of K. pneumoniae GLC29 in biodiesel glycerol. DCW, dry cell weight; I,3-PDO; I,3-propanediol

\begin{tabular}{|c|c|c|c|c|c|c|c|c|c|c|c|}
\hline \multirow{2}{*}{$\begin{array}{l}\text { Time } \\
\text { (h) }\end{array}$} & \multicolumn{3}{|c|}{ Obtained data } & \multicolumn{3}{|c|}{ Specific RATES } & \multicolumn{3}{|c|}{ Yields } & \multicolumn{2}{|c|}{ Productivity } \\
\hline & $\begin{array}{l}\text { DCW } \\
\text { (g/L) }\end{array}$ & $\begin{array}{l}\text { Glycerol } \\
\text { S(g/L) }\end{array}$ & $\begin{array}{l}\text { I,3-PDO } \\
\text { P(g/L) }\end{array}$ & $\begin{array}{l}\mu \mathrm{X} \\
\left(\mathbf{h}^{-1}\right)\end{array}$ & $\begin{array}{l}\mu S \\
\left(h^{-1}\right)\end{array}$ & $\begin{array}{l}\mu \mathbf{P} \\
\left(h^{-1}\right)\end{array}$ & $\begin{array}{l}A_{x / s} \\
(g / g)\end{array}$ & $\begin{array}{l}A_{x / p} \\
(g / g)\end{array}$ & $\begin{array}{l}Y_{p / s} \\
(g / g)\end{array}$ & $\begin{array}{l}P_{p} \\
\text { (g/L.h) }\end{array}$ & $\begin{array}{l}P_{\text {ox }} \\
\text { (g/L.h) }\end{array}$ \\
\hline 0 & 0.16 & 66.75 & 0 & 0 & 0 & 0 & 0 & 0 & 0 & 0 & 0 \\
\hline I & 0.27 & 64.73 & 0.17 & 0.35 & 7.24 & 0.62 & 0.05 & 0.61 & 0.09 & 0.17 & 0.11 \\
\hline 2 & 0.35 & 62.86 & 0.33 & 0.62 & 10.4 & 1.66 & 0.05 & 0.57 & 0.09 & 0.17 & 0.09 \\
\hline 3 & 0.7 & 57.43 & I.34 & 0.5 & 5.25 & 2.4 & 0.06 & 0.4 & 0.14 & 0.45 & 0.18 \\
\hline 4 & 1.05 & 55.48 & 3.71 & 0.4 & 1.85 & 2.48 & 0.08 & 0.24 & 0.33 & 0.93 & 0.22 \\
\hline 5 & I.54 & 53.54 & 6.57 & 0.26 & 3 & 1.96 & 0.1 & 0.21 & 0.5 & 1.31 & 0.28 \\
\hline 6 & 1.86 & 46.23 & 9.75 & 0.25 & 5.16 & 1.83 & 0.08 & 0.17 & 0.48 & 1.62 & 0.28 \\
\hline 7 & 2.48 & 34.34 & 13.38 & 0.19 & 4.07 & 1.47 & 0.07 & 0.17 & $0.4 I$ & 1.91 & 0.33 \\
\hline 8 & 2.79 & 25.99 & 17.06 & 0.11 & 3.01 & 1.36 & 0.06 & 0.15 & 0.42 & 2.13 & 0.33 \\
\hline 9 & 3.11 & 17.53 & 20.98 & 0.05 & 2.7 & I. 14 & 0.06 & 0.14 & 0.43 & 2.33 & 0.33 \\
\hline 10 & 3.11 & 9.23 & 24.16 & 0 & 0 & 0 & 0.05 & 0.12 & 0.42 & 2.42 & 0.29 \\
\hline 12 & 2.73 & 3.04 & 27.6 & 0 & 0 & 0 & 0.04 & 0.09 & 0.43 & 2.3 & 0.21 \\
\hline
\end{tabular}

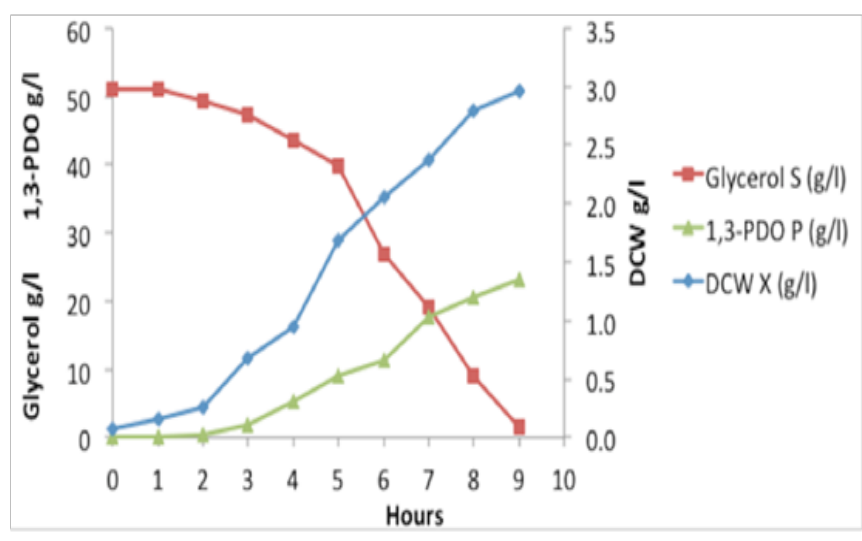

Figure 4 Kinetics of I,3-propanediol production using analytical grade glycerol. 


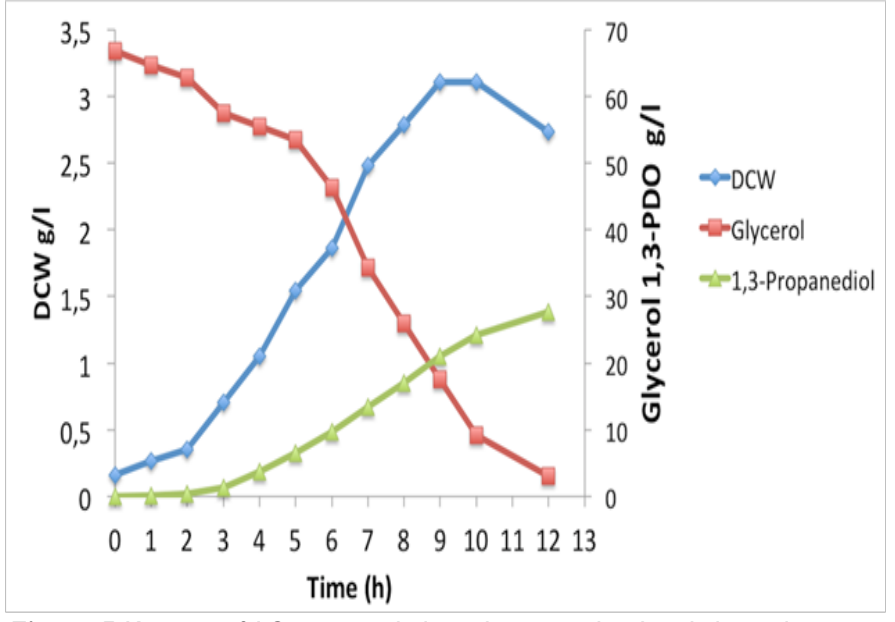

Figure 5 Kinetics of I,3-propanediol production in biodiesel glycerol.

\section{Conclusion}

Eleven media components were screened using Placket-Burman and Box, Hunter \& Hunter experimental design. Five components from media were considered significant to 1,3-propanediol production, glycerol, yeast extract, ammonium sulfate, vitamin B12, and fumaric acid. Inoculum concentration was fixed at $10 \%$, and $\mathrm{CaCl}_{2}$ at $5 \mathrm{mM}$. According to the DCCR experimental design, $45 \mathrm{~g} / 1$ of glycerol, $3 \mathrm{~g} / 1$ of yeast extract, $2 \mathrm{~g} / 1$ of ammonium sulfate and $0.25 \mathrm{~g} / 1$ of vitamin $\mathrm{B} 12$ had the best results for 1,3-propanediol production. It is recommended the use of concentrations lower than $49 \mathrm{~g} / \mathrm{l}$ of glycerol since the use of higher amounts resulted in lower 1,3-PDO concentration.

\section{Acknowledgements}

This work was sponsored by the São Paulo Research Foundation FAPESP/Brazil (Project 2011/01974-3 and 2011/21620-1) and performed at UNESP-Univ. Estadual Paulista.

\section{Conflict of interest}

The authors declare that they have no conflict of interest

\section{References}

1. Rathmann R, Benedetti O, Plá JA, et al. Biodiesel: Uma alternativa estratégica na matriz energética brasileira? II Semin. Gestão Negócios; 2005. 108 p.

2. Da Silva GP, Cristian J, Bolnerde Lima, et al. Production and productivity of 1,3-propanediol from glycerol by Klebsiella pneumoniae GLC29. Catal. 2014;257(Part 2):259-266.

3. Günther Fischer, Leo Schrattenholzer. Global bioenergy potentials through 2050. Biomass and Bioenergy. 2001;20(3):151-159.

4. Da Silva GP, Mack M, Contiero J. Glycerol: a promising and abundant carbon source for industrial microbiology. Biotechnol Adv. 2009;27(1):30-39.

5. Syed Shams Yazdani, Ramon Gonzalez. Anaerobic fermentation of glycerol: a path to economic viability for the biofuels industry. Current Opinion in Biotechnology. 2007;18(3):213-219.

6. Papanikolaou S, Muniglia L, Chevalot I, et al. Yarrowia lipolytica as potential producer of citric acid from raw glycerol. J Appl Microbiol. 2002;92(4):737-744.
7. Naresh Pachauri, Brian He. Value added utilization of crude glycerol from biodiesel production: a survey of current research activities. Portland, USA: Proc. ASABE Annu. Int. Meet; 2006.

8. Biebl H, Zeng AP, Menzel K, et al. Fermentation of glycerol to 1,3-propanediol and 2,3-butanediol by Klebsiella pneumoniae. Appl Microbiol Biotechnol. 1998;50(1):24-29.

9. Cárdenas DP, Pulido C, Aragón OL, et al. Evaluación de la producción de 1,3-propanodiol por cepas nativas de Clostridium sp. mediante fermentación a partir de glicerol USP y glicerol industrial subproducto de la producción de biodiésel. Rev Col Cienc Quím Farm. 2006;35(1):120 137.

10. Deckwer WD. Microbial conversion of glycerol to 1,3-propanediol. FEMS Microbiol Rev. 1995;16(2-3):143-149.

11. González-Pajuelo M, Meynial-Salles I, Mendes F, et al. Microbial conversion of glycerol to 1, 3-propanediol : physiological comparison of a natural producer, clostridium butyricum VPI 3266, and an engineered strain, clostridium acetobutylicum DG1 ( pSPD5 ). Appl Environ Microbiol. 2006;72(1):96-101.

12. Solaiman DK, Ashby RD, Foglia TA, et al. Conversion of agricultural feedstock and coproducts into poly(hydroxyalkanoates). Appl Microbiol Biotechnol. 2006;71(6):783-789.

13. Song YQ, Xu YZ, Hua D. 1,2 and 1,3 Propanediol, microbial production methods. Biosep Cell Technol Encicl. 2010;1:1-16.

14. Papanikolaou S, Aggelis G. Lipid production by Yarrowia lipolytica growing on industrial glycerol in a single-stage continuous culture. Bioresour Technol. 2002;82(1):43-49.

15. Rymowicz W, Rywińska A, Żarowska B, et al. Citric acid production from raw glycerol by acetate mutants of Yarrowia lipolytica. Chemical Papers. 2006;60(5):391-394.

16. González-Pajuelo M, Andrade JC, Vasconcelos I. Production of 1,3-Propanediol by clostridium butyricum VPI 3266 in continuous cultures with high yield and productivity. J Ind Microbiol Biotechnol. 2005;32(9):391-396.

17. Guneet Kaur, Srivastava AK, Subhash Chand. Advances in biotechnological production of 1,3-propanediol. Biochem Eng J. 2012;64:106-118.

18. Veerle ET Maervoet, Marjan De Mey, Joeri Beauprez, et al. Enhancing the microbial conversion of glycerol to 1,3-propanediol using metabolic engineering. Org Process Res Dev. 2011;15(1):189-202.

19. Irisappan Ganesh, Sambandam Ravikumar, Soon Ho Hong. Metabolically engineered Escherichia coli as a tool for the production of bioenergy and biochemicals from glycerol. Biotechnology and Bioprocess Engineering. 2012;17(4):671-678.

20. Nakamura CE, Whited GM. Metabolic engineering for the microbial production of 1,3-propanediol. Curr Opin Biotechnol. 2003;14(5):454 459.

21. Rock Oh B, Woo Seo J, Yeon Heo S, et al. Enhancement of ethanol production from glycerol in a Klebsiella pneumoniae mutant strain by the inactivation of lactate dehydrogenase. Process Biochem. 2011;47(1):156-159.

22. Sarat Babu I, Veera Venkata Ratnam B, Subba Rao S, et al. Optimization of medium constituents for the production of citric acid from byproduct glycerol using Doehlert experimental design. Enzyme Microb Technol. 2007;40(5):1367-1372.

23. Saitou N, Nei M. The Neighbor-joining method: a new method for reconstructing phylogenetic trees. Mol Biol Evol. 1987;4(4):406-425.

24. Felsenstein J. Confidence limits on phylogenies: an approach using the bootstrap. Evolution. 1985;39(4):783-791. 
25. Tamura K, Nei M, Kumar S. Prospects for inferring very large phylogenies by using the neighbor-joining method. Proc Natl Acad Sci USA. 2004;101(30):11030-11035.

26. Tamura K, Stecher G, Peterson D, et al. MEGA6: Molecular evolutionary genetics analysis version 6.0. Mol Biol Evol. 2013;30(12):27252729.

27. Schomburg I, Chang A, Placzek S, et al. BRENDA in 2013: Integrated reactions, kinetic data, enzyme function data, improved disease classification: New options and contents in BRENDA. Nucleic Acids Res. 2013;41(Database issue):D764-772

28. Moon C, Lee CH, Sang BI, et al. Optimization of medium compositions favoring butanol and 1,3-propanediol production from glycerol by Clostridium pasteurianum. Bioresour Technol. 2011;102(22):10561-10568.

29. Daniel R, Bobik TA, Gottschalk G. Biochemistry of coenzyme B12-dependent glycerol and diol dehydratases and organization of the encoding genes. FEMS Microbiol Rev. 1998;22(5):553-566.

30. Kajiura H, Mori K, Tobimatsu T, et al. Characterization and mechanism of action of a reactivating factor for adenosylcobalamin-dependent glycerol dehydratase. J Biol Chem. 2001;276(39):36514-36519.

31. Shibata N, Masuda J, Morimoto Y, et al. Substrate-induced conformational change of a coenzyme B 12 -dependent enzyme: crystal structure of the substrate-free form of diol dehydratase. Biochemistry. 2002;41(42):12607-12617.
32. Yamanishi M, Kinoshita K, Fukuoka M, et al. Redesign of coenzyme $\mathrm{B}(12)$ dependent diol dehydratase to be resistant to the mechanism-based inactivation by glycerol and act on longer chain 1,2-diols. FEBS J. 2012;279(5):793-804.

33. Barbirato F, Grivet JP, Soucaille P, et al. 3-Hydroxypropionaldehyde, an inhibitory metabolite of glycerol fermentation to 1,3-propanediol by enterobacterial species. Appl Environ Microbiol. 1996;62(4):1448-1451.

34. Hao J, Lin R, Zheng Z, et al. 3-Hydroxypropionaldehyde guided glycerol feeding strategy in aerobic 1,3-propanediol production by Klebsiella pneumoniae. J Ind Microbiol Biotechnol. 2008;35(12):1615-1624.

35. Zheng ZM, Hu QL, Hao J, et al. Statistical optimization of culture conditions for 1,3-propanediol by Klebsiella pneumoniae AC 15 via central composite design. Bioresour Technol. 2008;99(5):1052-1056.

36. Oh BR, Seo JW, Heo SY, et al. Fermentation strategies for 1,3-propanediol production from glycerol using a genetically engineered Klebsiella pneumoniae strain to eliminate by-product formation. Bioprocess Biosyst Eng. 2012;35(1-2):159-165.

37. Xiu ZL, Zeng AP. Present state and perspective of downstream processing of biologically produced 1,3-propanediol and 2,3-butanediol. Appl Microbiol Biotechnol. 2008;78(6):917-926. 